\title{
Controlling Singularity The role of online communication for young visual artists' identity management
}

by Karin Hansson

\section{Abstract:}

This article contributes to the literature on art, new media and identity by investigating the role online communication plays for young visual artists' identity management. Drawing from comprehensive sources on the Internet such as blogs, web pages, networking sites and digital magazines, as well as interview data from art students at the Royal Institute of Art in Stockholm, the article describes how artists deal with convergent contexts online, while addressing an exclusive public of cultural producers and simultaneously reaching for a broad cultural significance.

The study shows how the artists' discursive practices online foremost preserve a traditional artist's persona. The common denominator for the few students who used the web differently to communicate and collaborate was that they appeared in a variety of creative fields and also that they came from affluent families. However, to reach a high degree of consecration on the Swedish art field one should not communicate with a broad public online but with the right people that one first gets to know face-to-face at intimate social gatherings. Online communication is foremost used as a way of displaying belonging to the field, and to show that one recognizes a certain value - the singular artist.

\section{Contents}

Introduction

Section 1 The significance of communication technology in the arts

Section 2 Methods and data

Section 3 Results and analysis

Section 4 Discussion

Conclusion

Acknowledgements

\section{Introduction}

In the novel The City \& The City Mieville (2010), describes a place where two different cities coexists in the same geographical space and time without mixing, by the technique of un-seeing. This practice of not acknowledging people and objects because of certain characteristic is maintained by strong taboos, and in the novel, 
breaking the taboo is punished by social exclusion. I think this is an interesting allegory of how community can be maintained in situations that lack spatial, social, and temporal boundaries such as on the Internet, and where there is a threat - or potential threat - that parallel communities will collapse into each other. As an artist that has been working with web based projects since the 1990s, I am fascinated with how the global world of fine art maintains its exclusivity in the open environment of the Internet. To better understand how such a community can take place in the open, but be inaccessible without the right codes, this paper examines this process from the perspective of young artists' online self-performance.

In the arts, technology has always placed limits on how artwork is produced and distributed (Alexander, 2003). Art worlds are not isolated cultures but highly influenced by the changes in the surrounding society. The production of culture perspectives that have developed in sociology since the 1970s shows how the elements of culture are shaped by the systems within which they are produced and preserved (Peterson and Anand, 2004). The music business is an example of how external factors, such as information and communication technologies (ICTs), have altered production conditions and production methods (Alexander, 2003; Ebare, 2004; Zentner, 2006). In the case of fine art, online communication that makes it easy to manipulate, copy, distribute information, and interact with an audience has challenged the exclusivity of the artwork and the artist's role (Dahlgren, 2005; Paul, 2003).

Nowadays, Internet technically provides visual artists with an opportunity to directly communicate their art in a global context and to a wider audience than before without going through gatekeepers such as art critics, publishers and galleries. However, research contains very little information about how visual artists actually use the Internet, and in the few studies available, the Internet is primarily looked upon as a conventional platform for display (See e.g., Clarke III \& Flaherty, 2002; Mäkinen, 2009). When looking at comparable fields, such as the music industry where the production conditions have radically changed the business due to file sharing and online social networks, there is an extensive amount of research. The Internet gives musicians a direct channel to their fan base and enables collaborative networks at a distance, but the music industry is still an important gatekeeper when it comes to promoting the artist and setting the norms (Johnson, 2011). Marontate's (2005) research into a music technology program in a rural Canadian university shows how the Internet enables contact with the central music industry, at the same time as hegemonic norms create limits on the way online communications are used. Even though the students set up their own system of production and find alternative distribution channels, they still have to adapt to the conventions of their musical style to establish their career. In line with these findings, in their study of Australian musicians attitudes towards online social 
media like MySpace, Young and Collins (2010) show that even if the Internet has improved non-established musicians with the means to act without gatekeepers in the music industry, there is an incredible amount of work to create, distribute and generate money from music.

The Internet can also be looked upon as a style, a symbolic capital rather than a means of production. Uimonen's (2009) comprehensive study of an arts college in Tanzania shows how the use of technology is embedded in local and national relations and imaginations where the Internet not only has practical importance for getting access to the global art world, but also is a symbol that signifies belonging to this global context. Research on young people's use of social media also shows how different online contexts signify identity and belonging, and thus are structured by factors like class, age and race (Ahn, 2012; Ames et al., 2011; boyd, 2011b).

An art school is a place where artistic identity and discourses about art develop and where new media is on the curriculum; it is therefore an interesting place for studying young artists' use of the Internet. Here the artist's identity is shaped in relation to different ideas about the artist that exists in art students' different life contexts (Taylor and Littleton, 2008). In this study, I have therefore chosen to look at how young artists use different online communication tools and what these practices mean for the individual when establishing themselves as artists. During a five-month stay at the Royal Institute of Art in Stockholm (KKH) 2009/2010 I conducted a content analysis of students' $(\mathrm{N}=50)$ online artistic mediations and conducted semi-structured interviews with 10 of the students. In a follow-up study, I compared the result of the first study with informants' position on the artistic field over the following three years 2010-2013.

In the following Section 1, I begin by summarizing the theoretical background to the investigation; in Section 2, I describe my method. I summarize the results of the investigation in Section 3, and I discuss these results in Section 4. The last section provides a conclusion.

\section{The significance of communication technology in the arts}

As scholars from Goffman (1969) to Butler (2004) have shown, identity is not something stable but rather something performed and reproduced by constant repetition. By performing the norm for being an artist, one becomes an artist. The fact that identity is created does not however mean that the individual is free to change his or her identity; language and society's norms and rules place limits on what is conceivable and feasible (Foucault, 1982). The artist's norms are decided by the field of art, which according to Bourdieu (1990), includes all social actors sharing the same illusio, the belief in art and the importance of this field. Players may include policymakers, arts administrators, funding agencies, gallery owners, 
museum curators, the audience as well as artists themselves. To establish a career and acquire influence, what Bourdieu (1975, p. 30) calls a "succession strategy", is made by following the established rules of the field.

This field of art can be described as structured because of the opposition between two systems of production (Bourdieu, 1985). On the one hand, there is the field of large-scale production where the general audiences who are outside the realm of artistic producers, consume art with low cultural and economic value. On the other extreme there is the field of restricted production, where short-term economic gain is always secondary to recognition from other art producers (Figure 1). In order to enjoy a high reputation in this field, one should be independent and not allow oneself to be guided by the market or the rules of society.

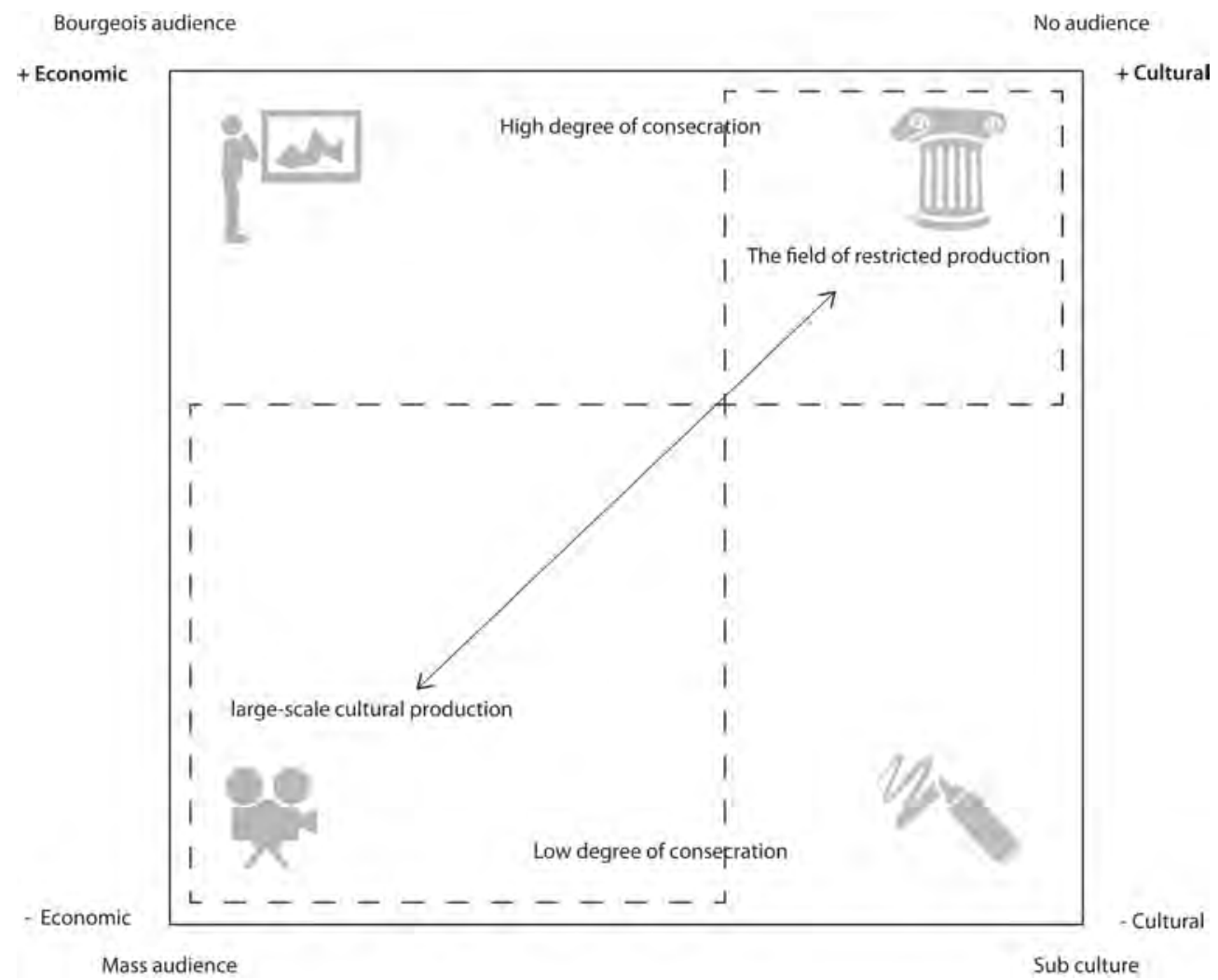

Figure 1. The field of art structured by audience size and levels of cultural and economic capital, and also by the field of large-scale cultural production and the field of restricted production.

An artist's reputation depends on how he or she navigates the artistic field, balancing between playing a role in the small circle of cultural producers on the field of restricted production and gaining a broader cultural significance and qualifications for e.g., much-needed scholarships and prestigious assignments. More detailed rules of the game, however, are unclear and in constant 
renegotiation. The ability to act in the field is limited by "the objective relations" in which the artist's identity is enacted, such as the dominant ideology, normative practices and power structures arising from the unequal distribution of artistic capital within the field. Bourdieu (2000) claims individuals adopt different strategies in the field depending on their habitus, meaning that individual variables such as ethnicity, gender and class determine the individual's possible strategies on the field. However, by obtaining a sound knowledge of the field, the individual can change his or her opportunities and also alter the rules of the game (Ibid). In this perspective, online communication changes the objective relations that limits the field, and could thus help some individuals with a high level of digital literacy in their succession strategy.

Bourdieu's view of the art world as a field in which different subfields and genres are fighting over a limited space has often been criticized as being too concerned with power and domination. Becker (1982) suggests a less structuralistic and more agent-centered idea of the field of art, as a network of smaller interconnected art worlds, consisting of individuals sharing the same interests and belongings. Becker's rhetoric is less warlike than Bourdieu's and more optimistic regarding the individual's opportunities to create his or her own conditions. He stresses the possibility of creating alternative art worlds when the established ones do not fit. In this perspective, new communication technologies, like the Internet, enables the establishment of new art worlds as it makes it easier to connect people with the same interest. Becker considers that every art world is a meaning-making culture with its own conventions and way of making art. These conventions create both limits and meaning, but without these boundaries, there is no art (Alexander, 2003; Becker, 1982).

Even though Bourdieu and Becker represent different perspectives in the sociology of art, they share an approach to art as a collective process. Heinich (2009) questions this collective perspective, suggesting that sociology should create explanations based on understanding the actors' own logic, where art most often is seen as an expression of a unique singular individual and not something collective. She also suggests that motivation in art has more to do with recognition of peers than an urge to gain power and dominate. Heinich (1997) claims that since modernism, singularity has been the central value regime of art. In her study of Van Gogh, Heinich shows how the modernistic concept of art is a matter of belief, where the artist functions like a martyr for a religion that worships singularity (Ibid). Singularity is not a stable regime but something that coexists in parallel with other values, such as the value regime of the artisan or the value regime of the professional networker. These unstable paradoxical belief systems are what constitute art. 
However, making art is also to make something public. An alternative concept to belief systems, fields or art worlds is therefore to talk about art as public spheres or just publics. Dewey uses the word public as something that is formed when a group of people recognizes each other when they perceive how something affects them collectively this gives them a reason to acknowledge each other and to come together (Dewey, 2012). A public is not only something that one belongs to, 'public' is also a property of something one makes, which is why it is an interesting term in research as it connotes an action that can be observed as it is made public. A public is nothing a person belongs to, but something people perform and participates in. The public, the place where identity and interest become public, is thus both a product of social or political action and a ground for further action. This means that the mode of public expression, whether it is a conversation, an online chat, an original painting or a printed book, is central for the forming of publics. Following the thoughts of Latour (2005), this means that not just humans are forming publics, communication technologies also have an active part.

Boyd (2011a, p. 39) points out how 'networked publics'- online social networks differ from other distribution forms as technology 'collapses' multiple contexts, making different publics collide as the lack of spatial, social and temporal borders makes it more difficult to control the environment and address specific publics. For the same reasons, the boundaries between the private and the public are more difficult to maintain (lbid). This convergent architecture of networked publics means that the individual continuously needs to present a coherent identity, that make sense from different publics' perspective, while acting this identity on different stages, and in different types of modalities (Papacharissi, 2010). Different stages for an artist can for example be blogs, articles, web pages or gallery openings. Types of different modalities are for example artworks, photos, reviews or interviews. Papacharissi (2010) suggests that mastering this art of distributed selfperformance creates a sense of place from an individual perspective. The enactment of a public self thus becomes an important literacy.

Identity-performance has been central to the arts since modernism, where artists' brands have been maintained over time and space through the publication of books and articles in newspapers controlled by gatekeepers such as art critics and art historians (Bydler, 2004). It is therefore interesting to see how individuals in this culture enact public selves online.

At the Royal Institute of Art in Stockholm (KKH) the emphasis is not on teaching a range of artistic techniques; the majority of students have already spent several years of art studies in preparatory art schools. The focus is more on career management, to create and maintain an identity for the artist on the art scene (Gustavsson et al., 2008). While the school offers the latest technology for artistic production such as 3D scanners and courses in animation and web production, 
$\mathrm{KKH}$ is also known as one of the most conservative art institutions in Sweden. Previous studies of the institution were conducted before the introduction of the Internet and mobile communication. Therefore, it is interesting to see how actors in this context adapt to the changes in communication technologies, and how they manage their professional identity expressed in aesthetics and other online practices. The main question is how young artists in this context use different online communication tools and what these practices means for the individual when establishing an identity as an artist.

\section{Methods and data}

To understand how the art students use online communication I look at their communication in a broad sense, from oral speech and clothing to social media. The focus is not so much on the singular artifact or practice, rather how artifacts and practices are used, organized and understood in a larger context. Here, I investigate how these discursive practices are reproduced, understood and developed by the actors in relation to existing social and economic positions. The initial study consists of a content analysis of the online mediations of fifty students, followed by semi-structured interviews with ten of the students. As a way of obtaining additional perspectives, the result of the content analysis was the starting point for the questions in the interviews. By combining the content analysis of online practices and students' own explanations of these practices, I compare a more quantitative overview of the practices with the individual actor's motivations. To see how student's online practice correlated with their career, the result of the first investigation was compared with a study of informants' official recognition in the dominating public sphere in established media the following three years.

The reason to study art students and not more established artists is that this gives us an opportunity to not only analyze those who succeed but also those who do not, as well as an understanding of the process of creating a field while establishing an artistic career. Here students from a larger diversity of backgrounds than established artists' try to make sense of the field, but also change it to make place for their unique perspective. Art students in higher education presumably share the same illusio, a similar belief in creating an artistic career.

The Royal Institute of Art is the highest and most prestigious education in art in Sweden and the reason why students most often have studied at several art schools before and might even have established themselves as professional artists. The school accepts about 25 students each year, the pool of students are usually about 25 years of age, with slightly more women than men. I have chosen to examine two groups, first-year and fifth-year students, in order to obtain a variation in age and at the same time an opportunity to make comparisons between students who have just entered the school and those who have 
completed 4 years. In this way, I can better understand how the educational setting affects students' cultural capital expressed in their online identity. The whole population in the two groups was examined; a total of 50 students; 23 first-year students (9 men and 14 women) and 27 fifth-year students (10 men and 17 women) were included in the study.

In the first study, I analyzed the representation of fifty art students' identities in the multimodal environment of the Internet in the form of text, images, sound, video, animation and typography on web pages, as well as in social networks. The material was collected through Google search, and by searching the most popular social networks. An 2009 Internet search combined much of the information that was publicly accessible for a person operating in Sweden and, as most of the newspapers and books were reviewed and marketed online, also included analogue media. Here, representation does not mean a representation of the physical body like an avatar in a game but rather, refers to identity-representation in a broad sense. It is not the single action that plays a role when establishing an online identity but the combination of different actions. Therefore, as opposed to most uses of visual methods, where researchers focus on a constrained aspect of the information like profile images on Facebook or text-based conversation in chat rooms, the focus was on the visual and verbal representation as a whole (see Appendix A). The type of information, whether it was a photo of a painting or an interactive video, was treated as discourse and thus a part of the message. The technical aspect of the information, how it was produced and how much interactivity was involved, were also important. Not only the actual representation, but the framing context was investigated, whether the students' name occurred in established art contexts on the web, in articles about art in Swedish newspapers, press releases to news bureaus and information from art institutions in alternative contexts, and whether students themselves present themselves as artists. It is also important to understand the interactive and social dimensions of social networks like Facebook and MySpace (See for example the discussion by Doostdar, 2004; Murthy, 2008), thus why I created active user identities in the most used social networks. However, I did not interact with informants online, or access their private communication in, for example, social media networks.

My own role as a member of the Swedish arts community has also been important for understanding the culture, balancing the disadvantages with being a native. For example, with the help of my network I could co-create a Facebook user with over 700 'friends' from the Swedish arts community, which enabled me to see how many Facebook friends the art students had in this network of established artists.

In addition, publically available information on a $5^{\text {th }}$ year art student could, for example, consist of: 
- Web page where domain is registered in own name, which shows that the page probably is self-produced. The web design is simple, black Courier size 10 on white background. The information is sparse; a resume containing a list of gallery shows, and photos that document art works (mostly sculpture) in the context of art galleries and museums.

- Company information at www.allabolag.se that index all Swedish companies.

- Network with 266 friends on Facebook, where at least 6 are established artists.

- No account in own name on Flickr, Myspace or Youtube.

- 3 articles in online local newspapers about a recent art project. These articles are mostly summaries of press information from an art hall and not written by art experts.

- Named as participant in a group exhibition at an art hall web page. Simplistic aesthetic, black Helvetica on white background. Provincial art hall.

Focus was on the information production that surrounds the artist and emphasizes the collective work in the art; the collective of critics, journalists, gallery owners and the public that co-creates the artist's identity. To investigate how the artist's online identity relates to different senders and contexts I not only looked at ideologies about the artist expressed in different discursive practices (the organizing and making of different forms of knowledge like text, form, color, technology, place and genre), but I also used the concept of frame to link discourse to a broader context that indicates a conscious sender as opposed to more un-reflected discursive practices (see Appendix B). I was also interested in the sender of the information and whether the art student seems to have control over the information.

The content analysis resulted in five ideal types representing different communication styles. To obtain contact with a heterogeneous group, as much as was possible in terms of communication style, 1 hour in-depth semi-structured interviews were carried out with students of each of the ideal types and of each cohort group, in total 10 students. The initial results were presented at a seminar at the school, on the school e-mail list, and were also discussed with a small group of seven students that formed a research circle about the artist's role.

To see if students' online presence had any effect on the informant's artist's career, I compared how they succeeded as artists the following three years (2010-2013), in terms of quality of exhibiting galleries and art halls, and communicated in established media as notices or reviews. The media analysis also gave me an overview of some of the contexts in which the students acted, for example, the articles and notices are often the result of galleries and art halls marketing efforts in relation to exhibitions or art rewards. 


\section{Results and analysis}

\subsection{Internet use: Co-existing artistic ideologies online}

The students represented a heterogeneous group in terms of forms of expression: from surreal paintings to charcoal drawings, performance, sound art and film. Many students used a diversity of expressions. They were also present in multiple online contexts. However, the most striking difference between the students in the online content was not the art genre or context, but type of online activity, thus, why I chose this as a starting point for a categorization. The categories are as follows: Visible for those whose activities created a coherent identity that made them easy to find and to define artistically; Unclear for those who were difficult to find and difficult to understand in terms of what kind of art they did; A few students were completely Invisible, as I couldn't find them online. Secondly, I grouped different ideas about the artist and art that was expressed in the material into three different categories; Artisan categorized material that showed the artist as someone that demonstrates skills, at for example painting nature or at editing video; Singular categorized material that portrayed the artist as a genial outsider who creates from his or her inner self; and Networker categorized material that signified the artist as someone that makes art in an art context.

The first group, Visible, was transparent in various ways; some students were primarily described by others, in newspaper articles about art exhibitions and the art schools' reports about who had obtained scholarships or entered higher education. This ideal type I called Icons. Icons could also frame themselves on self-produced websites, but if this were the case, they were presented as if someone else was the creator. The most common artistic ideologies in this group were Artisan and Singular, but the ideology Networker was also expressed. Figure 2 shows a webpage placing one of the art students in a Singular ideology as foremost, the sculptures are described as an expression of the artists' inner feelings and urge to express him or her self, and a journalist interprets the art and the artist. The article is based on an interview with the artist and written by a reporter that is covering culture in a broad sense; soccer, chorus performances and children playgrounds, and the article does not show any expertise in the way the text is written as it lacks references to contemporary art discussions. The art student was only present online in this manner, described by others and framed in an established art context showing a clear artistic identity, leaving no doubt that the art student was an authentic artist.

Another more active framing was performed by the students themselves by creating their own website and addressing visitors directly or by posting contributions in discussions on the web, acting more as cultural entrepreneurs in the way they engaged in collaborative work. I called this ideal type Agent. The most common ideology in this group was Networker. Figure 3 shows an artist's 
blog that I have categorized as Agent and Networker for several reasons. The blog is written by the artist in first person, it describes an art exhibition the artists has cocurated with other artists in an alternative non-commercial gallery, and it is published using a blog tool that enables a certain interactivity as it invites people to comment on posts and communicate with the artist. The artist was present online in other similar contexts, mentioned by other artist on their blogs, or as publisher of arty videos on YouTube.

The other large group of students was unclear as artists in various ways, as it was difficult to understand what kind of art they did: Some were easy to find but were present primarily as art students, framed as a name of a participant in various art school contexts like, for example, in press releases about student exhibitions. I called this ideal type Student. The ideal type Student did not have a clear artistic profile and the ideology Singular dominated the context. The ideal type were presented as a student and not as an artist and only appeared in student-related contexts. This could for example take the form of a name on a press release about a student exhibition, or a name on an art school's website. The ideal type Student occurred almost solely in the fifth year. All in all, twice as many students were unclear as artists in the fifth year as in the first year. This might sound odd, but it is important to understand the high status of The Royal Institute of Art (KKH) in the Swedish art context; to be a student at $\mathrm{KKH}$ is an important identity that might be the main legitimization of one's art. Figure 4 shows the framing of one Student, a web page from a well-known art school in Stockholm that prepares students for higher arts education, where the artist is listed as a former student. This person was present on two other sites, as a name on a press release from a student exhibition and as the receiver of an arts grant for students at $\mathrm{KKH}$.

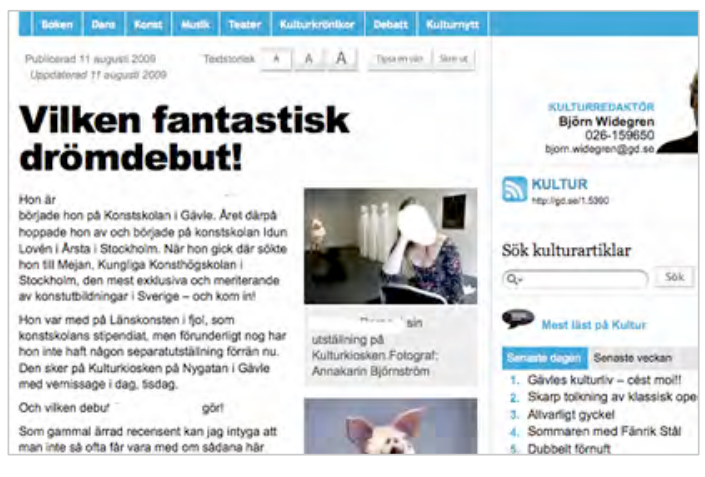

Figure 2. Icon, framed by journalist that emphasizes the student's artisan skills and singularity.

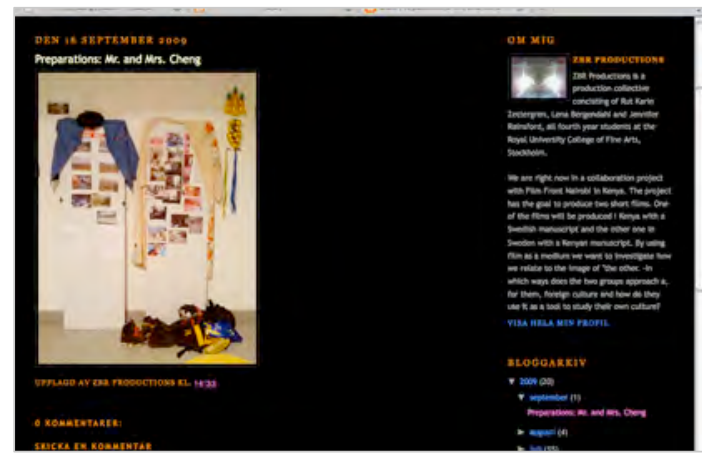

Figure 3. Agent, creating a blog about artistic collaborations. 


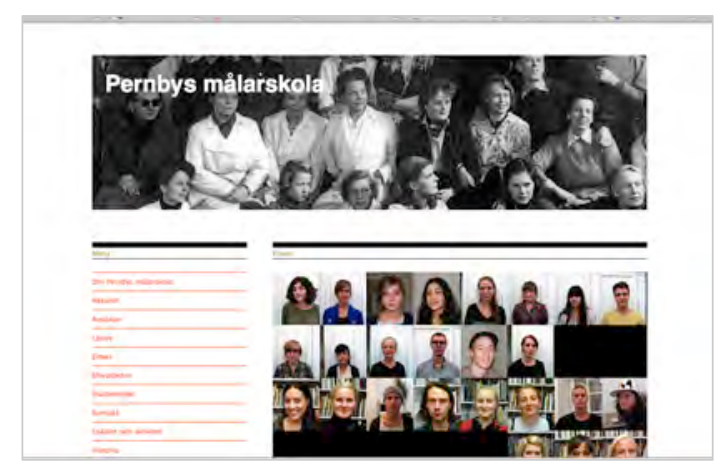

Figure 4. Student, framed by art institutions, here as an image and a name on an art school web page.

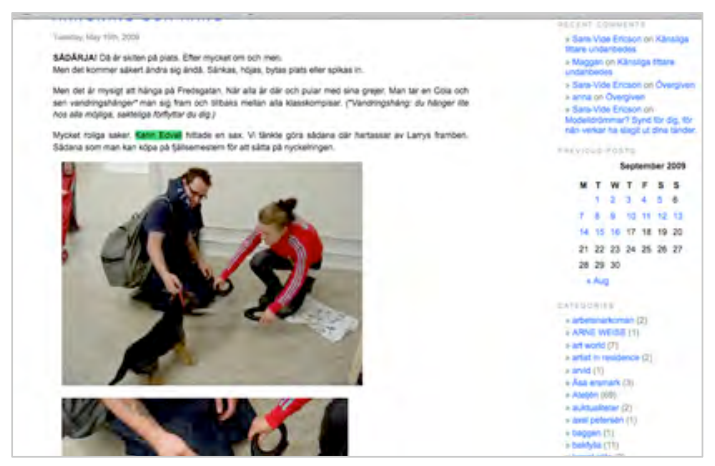

Figure 5. Indefinable, framed by other artists in arty contexts. Here in a blog as the name of a person that helps an artist installing an exhibition.

Another group was almost invisible as artists, but circulated in art contexts in different ways. This group I named Indefinable. The ideologies in this material were Singular or Networker. Among the Indefinable, the Singular ideology was strong first and foremost, because they demonstrated an inability to clearly communicate themselves and their art. As shown in Table 1, this group was largest in among the fifth year students. This group also expressed a Networker ideology since they showed that they moved around in several social art contexts, for example by being publishers of Flickr photo web pages documenting art exhibition openings or by having many people in Stockholm's art world as friends on the social network Facebook. Figure 5 is a screen shot of a blog that documents work with an art exhibition. Here an art student I categorized as Indefinable is mentioned as a person that helped install the exhibition. The exhibition is in a non-commercial alternative space and the other people that are mentioned or are in photos are from a younger generation of artists in Stockholm. The photos document the process off installing the exhibition and the blog presents the social aspects of the art space, which clearly positions this blog in an art discourse that has been around since the 1990s where focus is on the relational aspects of art rather than on the art object. The publication tool is a free open source tool that has just been slightly modified, which either shows that the blogger did not know how to change the layout, or that the aesthetic is a political statement pointing to the fact that they are using this particular free software and not a commercial one.

When looking at the students whose artist identity was clearly visible, it was the ideal type Icons whose discursive practice contained all the artist ideologies. The ideology Artisan was especially prominent in many cases. The material of the artwork or the craftwork elements of the work process could, for example, be discussed in reviews. The craft might be about drawing with charcoal in a certain complicated way or using $16 \mathrm{~mm}$ film to get the correct grey scale. In addition, the 
contextualization of the craft was important, for example it was important that the quality of the documenting photo was high or that the text about the artwork was well written. The ideal type Icon was largely framed through others, and in the description of the art and the artist first and foremost a Singular ideology emerged, in which the artist's individuality and differentness were highlighted and where others framed the art. This stereotype of an artist was foremost reproduced in local newspapers, where the journalists often are not experts on art (and therefore might reproduce a more popular notion of art than art experts would).

\begin{abstract}
"Because she is not on site it is the gallery's manager [name], who presents [name] and her work of art. [ $L$ He knows she wants to have her art without words, that it shouldn't be talked to pieces but rather must be allowed to speak for itself." (Quote from article about art exhibition in local newspaper)
\end{abstract}

In the above example, the framing is done first by the gallery manager whose story is interpreted and edited by the journalist. The narrative is that the artist is a shy oracle who cannot meet an audience directly but has to be interpreted by experts. What contradicts this image of the artist as framed by others is the fact that most Icons have their own website, which signals that they have an eye on things, and are someone that is more of a networker than an outsider. However, the art and the artist are often presented in the third person on the website, as if the owner of the website was someone other than the artist. Stylistically the same graphical language as for a museum of modern art is used. This language is more refined in fifth-year students' communications. In addition, the student category Agents can show, through their graphic language, that they belong to the art world, but they write in the first person, using a subjective voice. They not only use the web to directly promote themselves, but also as a tool for the organization of exhibitions and collaborative projects. Agents were twice as common among first-year students as among those who had entered their fifth year.

Table 1. Different types of visibility as artist on the Internet when searching for names of students at the Royal Institute of Art (KKH) autumn 2009, divided by ideal types.

\begin{tabular}{|l|l|l|l|l|l|}
\hline & Invisible & Unclear & \multicolumn{2}{l|}{ Clear } \\
\hline & & Indefinable & Students & Icons & Agents \\
\hline Ideologies & & $\begin{array}{l}\text { Singular } \\
\text { Networker }\end{array}$ & Singular & $\begin{array}{l}\text { Artisan } \\
\text { Singular } \\
\text { Networker }\end{array}$ & Networker \\
\hline Information control & & Yes, not visible & Poor & Yes, partly & Yes, largely \\
\hline Year 1 (23 students) & 1 & 4 & 2 & 9 & 7 \\
\hline Year 5 (27 students) & 3 & 4 & 9 & 8 & 3 \\
\hline Total & 4 & 8 & 11 & 17 & 10 \\
\hline
\end{tabular}




\subsection{Motivation}

\subsubsection{Contradictory opinions about the artist in interviews}

In the interviews, contradictory ideas about the artist came up, often from the same person, where artists' Internet use and general communication practices were placed in opposition to concepts about the artist.

Concepts about the artist The artist's practice

The artist as passive object The artist as active subject

Does not use Facebook Everyone uses Facebook

Lets the art speak Speaks for the art

Outsider

Networker

Takes big risks Pays close attention to detail

Doesn't keep up with marketingTakes the main responsibility for their PR

Needs no website Website essential

Doesn't care about appearanceMakes efforts to stick out

Not average

Middle class

Clearly definable art. Credible. Does a bit of each. Unserious.

The issue concerning appearance was also discussed in the interviews. The view was often that important contacts were established in informal social contexts where the artist's appearance and behavior became important. In this perspective the Internet had a secondary role; online presence functioned more like an extended business card.

The students were well aware of how an artist should behave but had difficulties describing the artist other than in negations. Here, the identity was not defined in duality with the other, rather the identity of the artist was to be the other; someone who does not use Facebook, does not keep up with marketing, does not look like all the others; someone who does not manage to dress themselves up, who does not arrive on time, and who does not have a bicycle helmet:

[Answer to question about appearance]

" Here, I am nearly the only one with a bicycle helmet! But it is perhaps because I am one of the older ones. Sometimes it feels as if people do not see you when you arrive with a bicycle helmet. Maybe a true artist should not be afraid to die." [laughs]

The art students that showed awareness of these conventions of the art world but had the self-confidence to ignore these limitations came from an upper-class or upper-middle class background. 
In the interviews, I unintentionally formulated the questions in a way that provoked an informative discussion. The formulation many questioned was my use of the word "marketing": if and how the students marketed themselves and their art. It was obviously wrong to talk in terms of marketing. Nobody wanted to be someone that "marketed" him or herself. However, when I asked how people knew about them and their art, I got other types of answers. When asking the students about artists they liked and why they liked them, they often mentioned young and not so established artists, unknown to a broader public.

[If you think about artists that you think are good, or are good at communicating, who are they?]

There are many young artists, and it is also contradictory to what I said earlier [about not being too private], but it's rather me who thinks it's a hassle if it is too personal. But I think of those young artists that blog or have websites where they post everything that happens in their art and what is happening in their lives.

[Do you have any examples?]

Sara-Vide, she has been here [at $\mathrm{KKH}$ ] before, and one that has been a student at Konstfack [University College of Arts, Crafts and Design] and one that goes here at Mejan now. But it's not as if I intrude into their lives, it is as a kind of role they have as they post. [---] As a sort of alter ego. It feels good too when you read it, it does not feel like it's too private, but as if I read some sort of history.

[But they are younger artists then?]

Yes.

[Do you think this is a way to get success?]

I do not know, but it appeals to me.

[ls this something you're willing to do yourself?]

Yes, I have set a goal, at least this year, to put up some sort of blog or website. (Student, year 5)

Here the student expresses identification with someone and she also gives her recognition. It was my question that made her aware that this practice could be a smart marketing tool. When asking about how they used information and communication technologies (ICT) to market their own art, the students were also reluctant to admit that they engaged in marketing more than having a web page. However, when talking about other things, they indirectly showed they were aware of the media and had a communication strategy. Most students used online communication to communicate with their network. Here a homepage or video clips were something they shared with a few but important acquaintances they met through their network at social gatherings, and not with a broad and unknown public.

But I have used this Vimeo, it's like YouTube but a little more serious, you can choose for yourself, here l've posted videos and then I locked it, so if I want someone to watch my stuff, the other day, a producer wanted to watch it, then I could send a link.

But I do not make it available via the website. I would not like to be exposed to others' eyes. It's a little stalker alert.

(Student, year 1) 


\subsubsection{The artist as a commodity online and alternative art worlds}

The preliminary result of the study was presented at an open seminar at $\mathrm{KKH}$. The changes, especially those between the first and last year were discussed. The students made me understand that some of these differences were because of structural changes at the school, and could not be explained by student's age or degree of art world socializing. We also discussed the attitudes in the student group towards the use of social networks like Facebook, and their negative attitudes towards marketing. An opinion came up that the reason people find their way to art often is a reaction against an over-rationalization in society, and a need to avoid the language of economics and politics. The use of online social networks or marketing strategies was seen as an expression of a trivialization of communication that was something one wanted to avoid. This fits well with the idea of the artist as being outside society, following his or her own singularity beyond the simplification of mass communication. However, it also shows how identification and recognition by peers is more important for these young artists than is the attention of a potential market.

The fact that so many 5 th year students did not use the web to communicate their artistic persona, does not seem to be due to lack of enterprise but on the contrary, indicates that the students, during their training, have acquired some of the codes and strategies that exist in the art world. Several of the students testified that teachers and professors did not see a personal website as being important.

\footnotetext{
"There are some who do not believe that one should have websites, some older, they say that one only requires a portfolio, and all that. Some people here at the school say so, I think, teachers and so. It was he [name] who is here at school now. [---] I do not think he has a website, but maybe he has, but he did not think we needed one.[---] No, I have never felt any pressure on me about it. It is mostly a discussion among students, but l've never heard a professor say that I ought to have one."
}

Despite the lack of pressure from teachers, the interviews showed that the students saw it as their task to frame their art carefully according to all the rules of art. All the students that were interviewed thought that having a website of their own was good; $35 \%$ of first-year students and $52 \%$ of fifth-year students had more or less developed their own websites and/or blogs. The aesthetics and framing on these pages showed most clearly that they placed themselves within the contemporary artistic field. Especially on the websites of fifth-year students, the art was framed in an exclusive art gallery, stripped down and simple, black and white. Usually the website did not contain too much information; it only included the most essential facts about the art and the artist written in the third person, sometimes with references to fashionable art philosophers. Almost none of the students worked with information technology as artistic material in and itself or with the opportunities for interactivity and collective action that technology makes possible. 
Several students highlighted the former student Sara-Vide Ericson's (2010) website as an example of good self-promotion. Here the artist, as part of an otherwise tightly maintained website, lays out images and comments about her own romantic artistic life in bohemian art studios and at gallery openings. Ericson has literally turned the artist identity into a product which is demonstrated among other works of art on the website. This blogging artist does not frame the art, but is rather a work of art in the form of a reality show from the art world.

Thus the ideology expressed about the singular artist has not changed appreciably, it is still a modernistic artist on display, but the discursive practices have changed, what the artist does. The artist is still an oracle that must be explained by others, but the contextualization made by art halls, art critics and journalists takes place online and can be difficult to overview. A portfolio in the form of a website therefore makes the curator's work easier. To pass as an authentic artist, it must however still look as if someone else does the framing, and the web design should not be an expression of a particular person, but look exactly as the web design of an art institution.

A few students, the ideal type Agent, actively communicated their art online; directly addressing visitors on their own blogs, and using social forums to organize collaborations, events and fundraising. When comparing the artistic genres and fields of activity of Agents and Icons an interesting pattern emerged. Agents represented a larger diversity in terms of artistic genres and were also more often active in multiple artistic fields (as shown in Appendix D). I had assumed that their online communication had to do with their experience in digital media tools in general, but it was not their skills in digital media that connected the Agents. Rather, the connection was the link to cultures that emphasize network and collective processes like open source, feminist activism or dance performance and especially that they had experiences from different art worlds and worked in several different genres. One student in the fifth year who acted as an Agent saw the Internet as a means of finding his own creative community:

It feels like a very difficult way to become a well-known artist who is mentioned in the big media, and regularly as well. So, the odds of being successful are very low. I think that it feels like a sense of security to believe that it is possible to find other ways too. I think it is possible. You don't have to be big, you can still find your audience.

[Where have you got your conviction from?]

I think it is much about the [Internet] culture that I grew up with. The fact that what I mostly listen to is smaller bands. I don't think they earn any big money, but they still keep on with their thing.

It is above all about trying to find your own niche. It is perhaps something the Internet has helped with too. Finding others who are doing similar things as you. [Yeah] And who are interested in the things you do. I do not see it as obvious to reach out to galleries and the classic art world. It [my work] borders onto many other areas, music, text, design, illustration and suchlike too. (Student, Year 5) 
This student's motivation is recognition among peers, rather than acquiring influence on the established field of fine art. This means that to use Internet to find others with similar interest or to create one's own alternative art world, if the more established one does not fit.

\subsection{Relationship between online presence and artistic career}

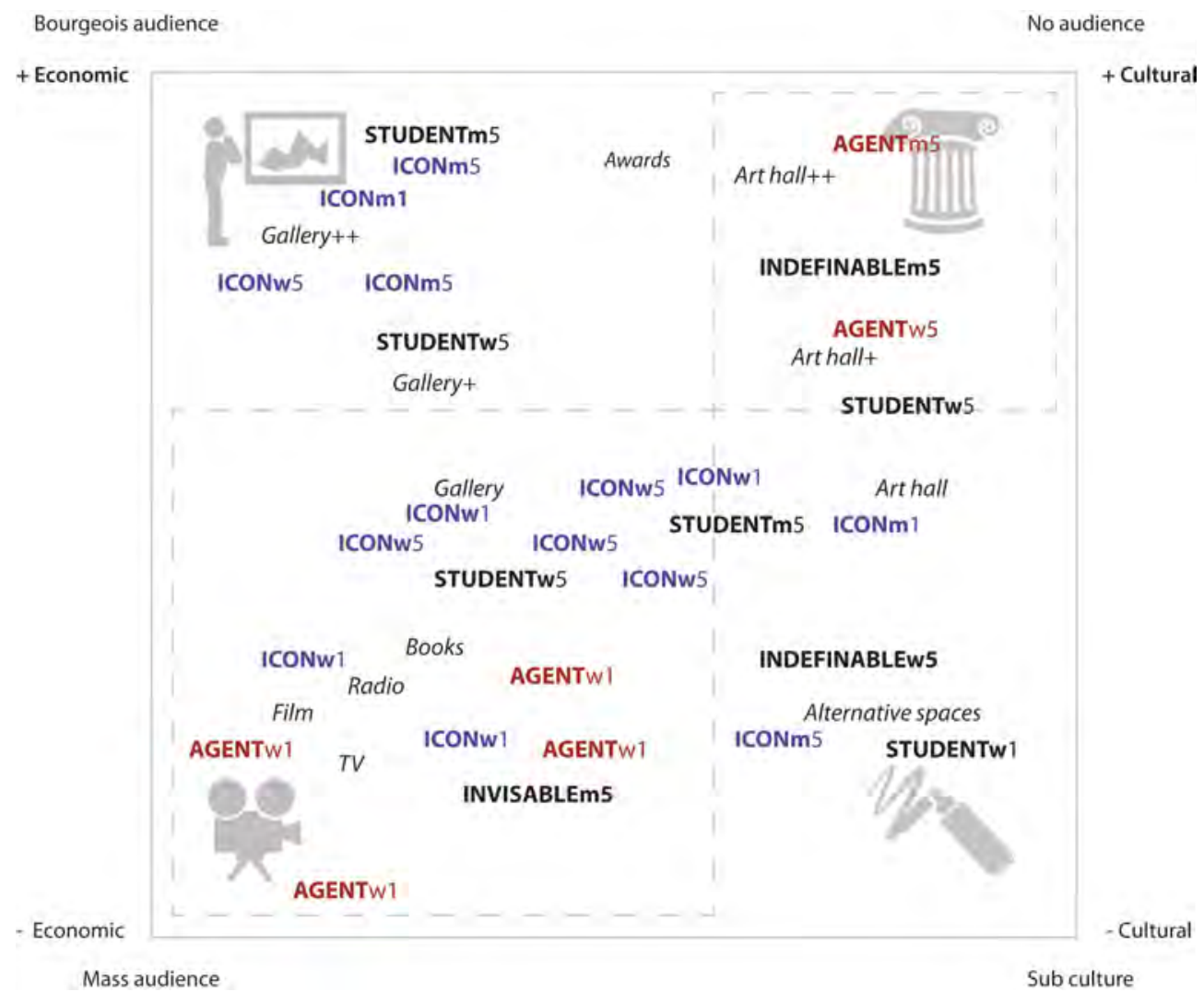

Figure 6: Informants position in the field in relation to different contexts for display: Ideal type, gender and year.

To see if online activity had any correlation with informants' artistic career I compared this with how the informants were described in established media three years (2010-2013) following the initial assessment. The content analysis was used to position the informants on a field of fine art where both type of audience and contexts for display were described in terms of economic and cultural capital. Not surprisingly, the result illustrated in Figure 6 shows there was a clear difference between the Agents and Icons informants regarding what type of career the media expressed, independent of artistic genre. This was especially clear among informants that reached a high degree of consecration, showing their works on prestigious art halls and galleries. The Icons foremost exhibited at commercial 
galleries, and were represented by a gallery. Just as this ideal type framed themselves at their homepage, as an object on display, their gallery now framed them. The Agents that were successful in having many mentions' in the media and had exhibited at prestigious venues, had no gallery support in doing so (at least not according to the articles), and they exhibited foremost at non-commercial art halls and temporary art events. Thus it was a correlation between online discourse and career path.

However, presumably, success in the art world is the result of a myriad of factors and thus why this correlation is an expression of so much more than online communication; it indicates that a certain behavior, partly documented online, creates a certain outcome.

\section{Discussion}

To sum up the investigation, a picture emerges where the art students' Internet presence contains two competing concepts of the artist: the romantic concept of the singular artist and the artist who is collectively created by the art world's institutions. This applies to someone who appears as an outsider but in practice is a networker. The ideology expressed is not something new, but the discursive practices have changed. For an older generation of artists, a personal website is, for example, considered vulgar. Artists should not promote themselves to a potentially broad audience. For a younger generation, a personal website is something that is considered valuable, but not as a mean of communicating directly to a wider audience but as a traditional artist's portfolio whose fastidious content requires a good understanding of contemporary art to be detectable. The most important interpretations and presentations of the art are still made by others. Informants that acted as Icons online, reproducing a traditional artist role, were also recognized by more prestigious galleries; this discourse was thus more successful from a career perspective. Performing as a traditional artist online became being an artist. Papacharissi (2010) suggests that from an individual perspective mastering self-performance creates a sense of place. This result shows how this self-performance also co-creates a shared space, as it recognizes and reproduces the values of the established art scene.

Agents did not receive less attention than Icons, but got it for other reasons. One informant did for example, get work as a program leader at a TV-show, another as an "artist blogger" in a magazine, thus still active as artists but not on the more restricted field of fine art. Other Agents were still in the field of fine art outside the commercial gallery sphere, taking part in thematic art exhibitions and projects in a diversity of venues, where the aim with exhibitions most often was to discuss a certain theme or contemporary tendency, and not as much to highlight the individual artist. 
What is interesting is how the students handled competing ideologies about how an artist should be. On the one hand, they saw the Internet as an obvious tool to self-access information about an art world that was difficult to gather and overview of. Even though they wanted to believe in the idea of the singular artist promoted by others, they doubted it, and as long as someone else was not doing the job, felt they had to promote themselves. On the other hand, following the logic of the more restricted field of cultural production, it is not important to reach a large audience but the right audience, and to exclude others. Communicating their own art on the Internet to a potential mass audience could damage their reputation and be seen as vulgar, as the most prestigious art is produced primarily for other cultural workers and an exclusive gallery market (Bourdieu, 1993; 2000). To gain legitimacy as a real artist they had to be accessible but play hard-to-get in order to not to be perceived as 'cheap.' The students' self-produced websites clearly signaled this norm through their formal language and their economical text. The websites were used as a way to frame the art as fine art, rather than to communicate with a broad public. When the art is shown outside the established institutions, like the art gallery or art museum, it becomes difficult to claim that what one does is fine art (Alexander, 2003; Becker, 1982). The art needs a context to be perceived as art, and as boyd (2011a) notes, the Internet collapses context; anyone can enter a web page without a preunderstanding of what is on display. This is probably why media practices, language style, and visual markers such as typeface and color are just as important as the artworks. These discursive practices signal to others in the arts community that the artist belongs to this social and art historical context, but is also a code that excludes people outside this context who do not recognize the importance of these communicative practices. This is consistent with Marontate's (2005) study of a music technology program in a Canadian university that showed how norms limit the use of technology even in a highly pro-technic art world. In his study, the students carefully framed themselves using the same styles and expressions as established music institutions to clearly signal their coveted position. The art simply becomes more conservative when the boundaries between contexts become blurred. Without context the artist have to perform the context to be recognized as an artist. Today, it is relatively easy to distribute one's own film or make a website with audio and animation without an entire production company. However, even though in theory, the technology gives the individual unlimited communication opportunities, the structurally organized positions the artist can take in order to be accepted as an artist are limited. A website that is too advertisement-like can, in this context, do more harm than good when trying to be seen and not 'un-seen' by peers and important gatekeepers in the world of fine art.

Another way to continue to be a rare artist with integrity and yet be an accessible and searchable commodity is to turn the artistic identity into an alter ego. However, the strategy of adopting an alias is not particular to new media, but a recognized 
tactic in the art world. Here one can see a strategy like Sara-Vide Ericson's (2010), who created an alter ego online, as a way of pushing the artist myth by exaggerating the myth of the artist in a staged, online narrative about young artists who eat noodles to save money to afford canvas. In the same time the artist actively controls the process as director of the story. However, this blogging artist does not really frame her art, rather she turns the conflict between being an outsider and being a networker into art: a work of art in the form of a reality show from the art world. The lack of an aura from an original artwork thus turns the artist into an icon for the art.

Some art students did not just reproduce the norms of the singular artist but took advantage of the convergent online contexts, and the means for collaboration with others. What united the students who acted as Agents is that they worked within many artistic disciplines and appeared to participate in multiple contexts. This anchoring in several different cultures can be interpreted as something that gives the individual perspective and space for renegotiating the norms for the group's identity. A space for negotiations that decreases the strength of the dominant ideology and, in the long term, might contribute to a renegotiation of the ideology. The role of technology is in this interpretation to destabilize norms, to facilitate the individual's movement between different art worlds, and to help establishing new ones enabling contacts with like-minded others. Another way of regarding the students' anchoring in several art worlds or sub-art fields is that it provides them with the opportunity to compare one field from another and in this way gain a deeper understanding of the structures. Bourdieu (2000) emphasizes the importance of understanding the field in order to change it. When the technology helps the user to look at the social space as a system that can have different sets of rules, it also paves the way for a renegotiation of the rules.

Important here is to see how this understanding of the field intersects with class. Students bent the rules for how an artist should be performed and instead of reproducing an idea of the artist as someone that needs to be interpreted by experts, used the Internet to communicate their art directly and as a way of organizing collaborations and events. These students not only acted on many different artistic fields, they also came from families with high amounts of cultural and social capital. Digital literacy is about having the right education to be able to navigate the cultural codes online, but also to be able to connect to the right social network. However, this digital literacy does mean, not from a constrained arts perspective, that the students that acted as Agents were successful as artists. When looking at informants' careers, the ones that attracted the most prestigious arts galleries and those who got different arts awards were foremost Icons. These students reproduced a more traditional artist identity online where it looked like they did not market themselves, but were framed by others. The Agents who were more successful in the art world were instead active on a non-commercial arena 
ruled by curators at art halls and museums. The online communication thus foremost seemed to help preserve a conservative artist's role on a commercial arena and artist aiming for a high degree of consecration to maintain the right social network, established on informal venues. The risk of being framed in the wrong context online was minimized by avoiding activity in contexts such as social networks like Facebook and Myspace, and by carefully framing the art as art.

\section{Conclusion}

In this study, I examined how art students manage their artistic identity online, how they use online communication and why, and the role these practices have in their succession strategy. In theory, online communication might make it difficult to maintain distinct social contexts regarding why the norms and practices that limit the field of art might be easier to change, and could thus help individuals that stands for this change. Following the logic of Becker's (1992) theory on art worlds, online communication could also be used as a way to abandon art worlds that do not fit new art worlds. However, instead the art students in this study primarily used the Internet as a way to maintain the norms and practices of fine art, motivated by belonging and recognition among peers and other culture producers as well as of potential success in the art establishment. The discourse regarding artists' homemade web pages reproduced the aesthetic and language of prestigious art galleries and museums and the art and the artists were framed by a minimalistic design and academic language. This controlled self-performance secured a position in the right art context.

The few actors that did not follow the norms regarding the singular artist interpreted by others but used the Internet in a more direct way to organize and collaborate, and to move from one context to another, did not gain recognition among the important galleries and were not awarded with grants.

As a possible way to change, online communications collapse contexts and make contact with alternative art worlds easier. The right family and social network makes it easier to make use of this opportunity to access a diversity of contexts and people. However, to reach a high degree of consecration on the Swedish art field, one should not communicate with a potential mass audience online but with the right people that you first get to know face to face at intimate social gatherings in the art world. One could assume that the Internet would diminish some of the uncertainty in the arts that often leads to conservatism but in this study, the Internet was not prominently used as a way of providing information about artists' skills in doing art works, but rather to show skills in performing an artist persona. Selfperformance online could instead be seen as a way of communicating belonging, to show that one recognizes a certain value - the singular artist - and to be recognized as an embodiment of this value. To avoid participative online contexts 
such as social networks and blog tools, and to maintain a minimalistic looking website was a way to take control over how one's persona was mediated and to establish oneself in the right discourse. The online communication was thus part of a broader discursive practice that involved skills in typography as well as in being secretive. In this discourse, an important artistic statement was to not give out information. The characteristic minimalistic aesthetics and not easily penetrated language coded with references to art philosophy thus made it possible to maintain context even where social, spatial, and temporal boundaries were lacking, as it was inaccessible for groups without the right codes and conventions.

\section{Acknowledgements}

The research was funded by the Swedish Research Council FORMAS, project number 2011-3313-20412-31; and by Strategic funds from the Swedish government within ICT - The Next Generation.

\section{About the author}

Karin Hansson (khansson@dsv.su.se), Ph.Lic., artist, curator and PhD student at The Royal Institute of Arts in Stockholm and at the Department of Computer \& System Science, Stockholm University. Her research focus is artistic methodologies and online participatory processes.

E-mail: khansson@dsv.su.se

\section{References}

June Ahn, 2012. "Teenagers and Social Network Sites : Do off-Line Inequalities Predict Their Online Social Networks?" First Monday, 1 volume 7, number 1, pp. 1-14.

Victoria D. Alexander, 2003. Sociology of the Arts: Exploring Fine and Popular Forms. Wiley-Blackwell.

Morgan G. Ames, Janet Go, Joseph Jofish Kaye and Mirjana Spasojevic. 2011. "Understanding Technology Choices and Values through Social Class." In CSCW 2011 Proceedings, pp. 55-64.

Howard S. Becker, 1982. Art Worlds. University of California Press.

Pierre Bourdieu, 1975. "The Specificity of the Scientific Field and the Social Conditions of the Progress of Reason." Social information science volume 14, issue 6, pp. 19-47.

Pierre Bourdieu, 1985. "The Market of Symbolic Goods." Poetics, volume 2, April, pp. 13-44.

Pierre Bourdieu, 1990. The Logic of Practice. Cambridge: Polity. 
Pierre Bourdieu, 1993. The Field of Cultural Production: Essays on Art and Literature. ed. Randal Johnson. Columbia University Press.

Pierre Bourdieu, 2000. Konstens Regler: Det Litterära Fältets Uppkomst Och Struktur [Les Règles de L'art.]. Stehag: B. Östlings bokförl. Symposion. danah boyd, 2011a. "Social Network Sites as Networked Publics: Affordances, Dynamics, and Implications." In A Networked Self, ed. Zizi Papacharissi. Routledge, pp. 39-58.

danah boyd, 2011b. "White Flight in Networked Publics? How Race and Class Shaped American Teen Engagement with MySpace and Facebook." In Race After The Internet, eds. Lisa Nakamura and Peter A. Chow. Routledge, pp. 203-22.

Judith Butler, 2004. Undoing Gender. Psychology Press.

Irvine Clarke III and Theresa B. Flaherty, 2002. "Marketing Fine Art on the Internet: Issues and Ideas." International Journal of Nonprofit and Voluntary Sector Marketing, volume 7, issue 2, pp. 146-60.

Anna Dahlgren, 2005. Fotografiska Drömmar Och Digitala Illusioner: Bruket Av Bearbetade Fotografier I Svensk Dagspress, Reklam, Propaganda Och Konst under 1990-Talet [Photographic Dreams and Digital Illusions: The Use of Altered Photographs in the Swedish Daily Press, Advert]. Stockholm: Brutus Östlings Bokförlag Symposion.

John Dewey, 2012. The Public and Its Problems: An Essay in Political Inquiry. Penn State Press.

Alireza Doostdar, 2004. “The Vulgar Spirit of Blogging': On Language, Culture, and Power in Persian Weblogestan." American Anthropologist, volume 106, issue 4, pp. 651-62.

Sean Ebare, 2004. "Digital Music and Subculture: Sharing Files, Sharing Styles." First Monday, volume 9, issue 2.

Sara-Vide Ericson, 2010. "Sara-Vide Ericson." http://saravide.se/, accessed 26 October 2010.

Michel Foucault, 1982. "The Subject and Power." Critical Inquiry, volume 8, issue 4, pp. 777-795.

Erving Goffman, 1969. The Presentation of Self in Everyday Life. London: Penguin Press.

Martin Gustavsson, Mikael Börjesson, Raoul Galli, Andreas Melldahl, Christina G. Wistman, Barbro Andersson, and Marta Edling, 2008. "Utbildnings- Och Kultursociologiska Studier Av Konstnärer Och Konstutbildningar I Sverige 1945-2007 [Educational and Cultural Sociological Studies of Artists and Arts Education in Sweden 1945-2007]." Praktiske Grunde 1.

Geoffrey Johnson, 2011. "Download This : Artist Development and Interconnectivity in the Internet Age." Review Literature And Arts Of The Americas, volume 1, issue 1, pp. 2-26. 
Bruno Latour, 2005. Clarendon Clarendon lectures in management studies Reassembling the Social: An Introduction to Actor-Network-Theory. Oxford University Press.

Helena Mäkinen, 2009. "Web Sites as New Communications Devices in the Arts Field." In Culture as Innovation: The Search for Creative Power in Economies, eds. Juha Kaskinen and Riikka Saarimaa. Turku, Finland: Finland Futures Research Centre, Turku School of Economics, 47-66.

Jan Marontate, 2005. "Digital Recording and the Reconfiguration of Music as Performance." American Behavioral Scientist, volume 48, issue 11: 1422-38. Dhiraj Murthy, 2008. "Digital Ethnography: An Examination of the Use of New Technologies for Social Research." Sociology, volume 42, issue 5, pp. 83755.

Christine Paul, 2003. Digital Art (World of Art). Thames \& Hudson.

Richard A. Peterson and N. Anand. 2004. "The Production of Culture Perspective." Annual Review of Sociology, volume 30, issue 1, pp. 900-907.

Stephanie Taylor and Karen Littleton, 2008. "Art Work or Money: Conflicts in the Construction of a Creative Identity." The Sociological Review, volume 56, issue 2, pp. 275-92.

Paula Uimonen, 2009. "Internet, Arts and Translocality in Tanzania." Social Anthropology, volume 17, issue 3, pp. 276-90.

Alejandro Zentner, 2006. "EconPapers: Measuring the Effect of File Sharing on Music Purchases." Journal of Law \& Economics, volume 49, issue 1, pp. 6390. 


\section{Appendix A}

\section{Example of analysis of the visual and verbal representation as a whole}

Example of how different discourses of the artist are expressed on personal web pages through a combination of graphical styles, technologies and language.

\section{Example 1: Agent}

A blog with a background in different shades of gray-blue. In the middle a picture of a landscape painting in similar style as the background. The picture is framed with a black border on a gray field in a different tone than the background. The blog's content-rich menu bar consists of white text on a green-blue framed box with a shaded frame. The text is a bold san-serif. The language is a mixture of blog's default English menu and descriptions in Swedish. There are several icons that indicate that there is more information to see and that a larger picture can be downloaded.

Here the artist has obviously used a blog tool and added a template that matches the style of the paintings on display, in a matter that does not follow the conventions. The blog is situated on another person's personal homepage. The site looks self-made and the introduction text is also very personal and direct:

"Hi everyone! Welcome to my gallery on the net! My name is [...] and can be reached at [...]. Do not hesitate to contact me if you want to know anything about any painting! Furthermore, you can comment on the pictures if you click on them, just so you know! :)"

The language is Swedish which narrows the target group. The title states "artist" [konstnär] and the artworks are also labeled in different categories, like paintings, drawings, photos. But there is no information on size or price. But each artwork can be rated and commented on.

Discourses about the artist: Here the artist is an active person who can speak for herself to anyone interested. The art is nothing exclusive, but a craft, and the artist is an artisan. She shows mastery in different genres but doesn't seem to have any certain theme she follows. What she doesn't master though is the language of fine art, as she clearly doesn't understand the codes.

\section{Example 2: Icon}

A web page with a white background. At the top a simple menu item with a few headlines in capital letters in a gray san-serif. Centered in the white field, a picture from an art gallery that displays the student's paintings.

Here the style is much more strict. It does not follow the styles or colors of the art works on display, but rather contrasts them. It looks as though a skilled graphic designer has been involved in the creation of the website, but probably it is the teacher in web design at the school that has been helpful. It is a static page without the possibility to comment or rate the content. The domain name is the same as the artist's name and is also owned by the artist and hosted on a web hotel. The background is white and there is plenty of space around text and images, just like in an exclusive art catalogue. The purpose of the site is never declared, the information given is minimal; contact information, brief cv, images of work. Each work is presented together with the title, production year, size and material. There are no prices, but the site refers to an art gallery. There are no labels on the work. Different genres of art, foremost paintings and animations, are simply presented as "works". Several of the artworks are documented in an art context that shows that the art works have been on display in environments that look like art museums and galleries. Links to more information go to mediations by others, like press releases from art institutions.

Discourses about the artist: Here the artist is an exclusive object who does not speaks directly to her audience. The target group speaks English, and the tone is not personal. The artworks and the titles of the artworks connote physicality, self-image and feelings, and are all concerned with the same theme. 


\title{
Appendix B
}

\section{Example of data collection sheet for a student}

\author{
Year 1 \\ Student B \\ Ideology \\ Singular; does not self publish artworks; the theme in the art is to \\ express own strong feelings. \\ Networker; Active in social media, present in many databases \\ Discursive practice \\ Art genre: Film \\ Graphical style: High art dominates; simple spacious design, white \\ background, san-serif typeface like Helvetica or Arial, brief information. \\ Contexts: Uses Facebook and social networks about film. Shows up in \\ several film databases. Name on film school web page. Articles in \\ newspaper. Listed on the Art Grants Committee homepage. \\ Information both in Swedish and in English. \\ Does not seem to have her own web page. \\ Framing \\ The student does approximately $2 / 6$ of the framing, $3 / 6$ is done by \\ institutions like film databases and art schools, $1 / 6$ by journalists. \\ Control, target \\ Low control over the information. Target group is the professional art \\ network. \\ Distribution \\ Over 120 different sites of information \\ Comment \\ The student has worked with a famous filmmaker, which is why the \\ student's name appears in many film databases. This makes the \\ student seem more established than what might be the fact. At first I \\ thought this student was very active, but when I got a better \\ understanding of how the film databases operate I understood that the \\ student had no active part in this framing.
}




\section{Appendix C}

\section{Fields of art the students are active on and art genre}

Table A1. Representation of fields of activity and artistic genres among the ideal types Agent and Icon.

\begin{tabular}{|l|l|l|l|}
\hline Fields of activities for Icons & Field : Genre (Icons) & Fields of activities for Agents & Field : Genre (Agents) \\
\hline Icon 1: Visual Art + Film & Fashion: Fashion design & Agent 1: Visual Art & Film: Experimental film \\
Icon 2: Visual Art & Film: Script writing & Agent 2: Visual Art & Film: Scenography \\
Icon 3: Visual Art & Music: Rock music & Agent 3: Visual Art + Film & Literature: Poetry (2) \\
Icon 4: Visual Art & Visual art: Drawing (2) & Agent 4: Visual Art + Literature & Photography: Photo art \\
Icon 5: Visual Art + Music & Visual art: Painting (8) & Agent 5: Visual Art + Literature & Photography: Photo journalism \\
Icon 6: Visual Art & Visual art: Installation & Agent 6: Visual Art+ Photography & Politics: Feminist activities \\
Icon 7: Visual Art & Visual art: Animation & Agent 7: Visual Art+ Politics & Visual art: Conceptual art \\
Icon 8: Visual Art & Visual art: Performance & Agent 8: Visual Art + Film & Visual art: Curating \\
Icon 9: Visual Art + Fashion & Visual art: Sculpture & Agent 9: Visual Art & Visual art: Drawing (3) \\
Icon 10: Visual Art & Visual art: Sound (2) & Agent 10: Visual Art + Photography & Visual art: Painting (2) \\
Icon 11: Visual Art & Visual art: Video (2) & & Visual art: Performance (2) \\
Icon 12: Visual Art & & & Visual art: Sound art \\
Icon 13: Visual Art & & & Visual art: Street art \\
Icon 14: Visual Art & & & Visual art: Video (2) \\
Icon 15: Visual Art & & & Visual art: Photography (2) \\
Icon 16: Visual Art & & & \\
Icon 17: Visual Art & & & \\
\hline
\end{tabular}

